\title{
Thresholds in Distributive Justice
}

\author{
Dick Timmer \\ Utrecht University, Utrecht, the Netherlands \\ k.d.timmer@uu.nl
}

\begin{abstract}
Despite the prominence of thresholds in theories of distributive justice, there is no general account of what sort of role is played by the idea of a threshold within such theories. This has allowed an ongoing lack of clarity and misunderstanding around views that employ thresholds. In this article, I develop an account of the concept of thresholds in distributive justice. I argue that this concept contains three elements, which threshold views deploy when ranking possible distributions. These elements are (i) the level of the threshold, (ii) what constitutes the value of the threshold, and (iii) how benefits above and below the threshold must be allocated. I highlight three contributions that this particular account of thresholds makes: it clarifies the nature of the shift that occurs at the threshold; it resolves a common misunderstanding about headcount principles; and it shows how the arbitrariness objection can be met.
\end{abstract}

\section{Introduction}

Many theories of distributive justice deploy thresholds. Some of these theories say that people should have enough of certain goods - enough to be free from deprivation, for example, or enough to achieve some higher standard of living. ${ }^{1}$ Other theories say that people should not have too much of certain goods, such as income and capital. ${ }^{2}$ As I write this, for example, Amazon CEO Jeff Bezos is worth $\$ 192$ billion. Meanwhile, hundreds of millions of people are living in extreme poverty. Threshold concepts such as deficiency and excess can help explain and evaluate what is wrong with this situation and how we should act in light of it.

\footnotetext{
${ }^{1}$ For example, see Larry S. Temkin, Equality, Priority, and the Levelling-Down Objection, in The Ideal of Equality, ed. by Matthew Clayton and Andrew Williams (New York: Macmillan, 2000), pp. 126-61; Martha C. Nussbaum, Poverty and Human Functioning: Capabilities as Fundamental Entitlements, in Poverty and Inequality, ed. by David B. Grusky and Ravi Kanbur (Stanford: Stanford University Press, 2006), pp. 47-75; Paula Casal, Why Sufficiency Is Not Enough, Ethics, 117.2 (2007), 296-326.

${ }^{2}$ For example, see Ingrid Robeyns, Having Too Much, in NOMOS LVI: Wealth. Yearbook of the American Society for Political and Legal Philosophy, ed. by Jack Knight and Melissa Schwartzberg (New York: NYU Press, 2017), pp. 1-44; Danielle Zwarthoed, Autonomy-Based Reasons for Limitarianism, Ethical Theory and Moral Practice, 21.5 (2018), 1181-1204; Dick Timmer, Limitarianism: Pattern, Principle, or Presumption?, Journal of Applied Philosophy (forthcoming).

(C) The Author(s), 2021. Published by Cambridge University Press. This is an Open Access article, distributed under the terms of the Creative Commons Attribution licence (http://creativecommons.org/licenses/by/4.0/), which permits unrestricted re-use, distribution, and reproduction in any medium, provided the original work is properly cited.
} 
Despite the prominence of thresholds in distributive justice, there is no general account of 'thresholds' as such. ${ }^{3}$ My aim in this article is to propose a precise and comprehensive account of distributive thresholds and to offer the conceptual vocabulary to aid ongoing debates about views that deploy them. Such an account provides important insights into current debates on distributive justice. It clarifies ongoing misunderstandings around views that deploy thresholds and defends threshold views against common objections.

To illustrate, one common classification of theories of distributive justice distinguishes between egalitarianism, prioritarianism, and sufficientarianism, and renders sufficientarianism in particular to be a threshold view. Yet this neglects the fact that most specifications of egalitarianism and prioritarianism also rely on thresholds, for example because they support some sort of social minimum. ${ }^{4}$ Furthermore, the lack of a unifying formal account of thresholds obscures what renders a threshold distinct from other sorts of devices such as weightings or deontic constraints. This has given rise to widespread misunderstandings of principles that are often associated with thresholds, such as the role that lexical priority and headcounting should play in threshold views. ${ }^{5}$ Subsequently, without a clear understanding of thresholds, prominent but defeasible objections to thresholds, such as the objection that thresholds are arbitrary, resurface wherever thresholds are deployed. ${ }^{6}$ In light of all this, it is crucial to have a comprehensive account of thresholds to help us better understand some of the key issues in current debates about thresholds in distributive justice.

This article is structured as follows. In $\$ 2$, I introduce threshold views in distributive justice. In $₫ 3$, I distinguish between three elements of the concept of a threshold, namely the level of the threshold (\$3.1), what constitutes the value of the threshold $(\$ 3.2)$, and how benefits above and below the threshold must be allocated $(\$ 3.3)$. In the subsequent sections, I highlight three contributions of this account of thresholds: it clarifies the nature of the shift that occurs at the threshold ( $\$ 4$ ); it resolves a common misunderstanding about headcount principles and shows why, contrary to a received wisdom about such principles, sufficientarians should endorse headcounting ( $\$ 5)$; and it shows how the arbitrariness objection can be met $(\$ 6)$. In $\$ 7$, I conclude by setting out the implications for threshold views in distributive justice.

\footnotetext{
${ }^{3}$ Thresholds are certainly widely discussed, most prominently in the literature on sufficientarianism. But those debates revolve around the question of which substantive commitments proponents of threshold views, and of sufficientarianism in particular, must endorse. They do not concern the more general issue of what sort of role thresholds play in distributive justice. The debate about whether sufficientarians should endorse the 'negative thesis', which says that justice is indifferent to what happens above the threshold, is an example of this. See Casal, Why Sufficiency Is Not Enough; Liam Shields, The Prospects for Sufficientarianism, Utilitas, 24.1 (2012), 101-17; David V. Axelsen and Lasse Nielsen, Essentially Enough: Elements of a Plausible Account of Sufficientarianism, in What Is Enough? Sufficiency, Justice, and Health, ed. by Caterina Fourie and Annette Rid (Oxford: Oxford University Press, 2017), pp. 10120; Lasse Nielsen, Shielding Sufficientarianism from the Shift, Law, Ethics and Philosophy, 5 (2017), 142-53; Robert Huseby, Sufficiency and the Threshold Question, The Journal of Ethics, 24 (2020), 207-23.

${ }^{4}$ For example, see Temkin; Campbell Brown, Priority or Sufficiency . . . or Both?, Economics and Philosophy, 21.2 (2005), 199-220; Martin O'Neill, What Should Egalitarians Believe?, Philosophy \& Public Affairs, 36.2 (2008), 119-56. See also $\$ 2$.

${ }^{5}$ See $\$ 5$.

${ }^{6}$ See $\$ 6$.
} 


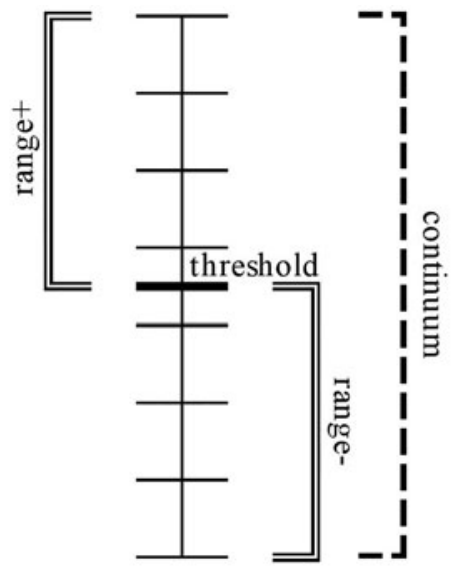

A. Single-threshold view

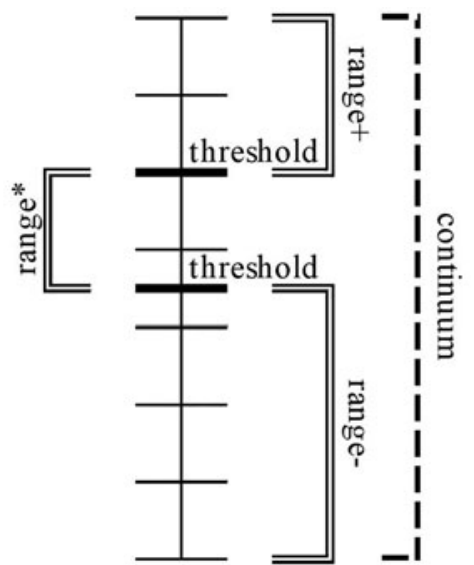

B. Multi-threshold view (vertical)

Figure 1. The structure of threshold views in distributive justice.

\section{Threshold views in distributive justice}

Theories of distributive justice specify what a just allocation of distributable goods, such as welfare, resources, or capabilities, requires. ${ }^{7}$ Such theories are threshold views if they posit a threshold in specifying this. Thresholds are crucial for understanding many debates in distributive justice, ranging from those about abstract distributive patterns to those about applied debates in the contexts of healthcare, education, and climate ethics. ${ }^{8}$

Stuart White gives an insightful example of a claim that illustrates the pervasiveness of thresholds in distributive justice: 'People should not be allowed to starve in the streets. ${ }^{9}$ This claim suggests that people should have access to at least some minimum standard of living, which means that some threshold should be met. This commitment to a threshold is part of influential specifications of egalitarianism, prioritarianism, utilitarianism, libertarianism, and relational egalitarianism, among other views. ${ }^{10}$

\footnotetext{
${ }^{7}$ Where I am agnostic between different metrics (or 'currencies') of distributive justice, I will use the term 'distributable good' or 'good'. This generic term is intended to capture all possible metrics and proxies for that metric.

${ }^{8}$ For example, see Henry Shue, Subsistence Emissions and Luxury Emissions, Law \& Policy, 15.1 (1993), 39-60; Madison Powers and Ruth R. Faden, Social Justice: The Moral Foundations of Public Health and Health Policy (Oxford: Oxford University Press, 2006); Cécile Fabre, Whose Body Is It Anyway? Justice and the Integrity of the Person (Oxford: Oxford University Press, 2006); Elizabeth S. Anderson, Fair Opportunity in Education: A Democratic Equality Perspective, Ethics, 117.4 (2007), 595-622.

${ }^{9}$ Stuart White, Social Minimum, in The Stanford Encyclopedia of Philosophy, ed. by Edward N. Zalta, Winter 2015.

${ }^{10}$ For example, see Brown, Priority or Sufficiency . . . or Both?; Robert E. Goodin, Utilitarianism as a Public Philosophy (Cambridge: Cambridge University Press, 1995); Elizabeth S. Anderson, What Is the Point of Equality?, Ethics, 109.2 (1999), 287-337; John Rawls, Justice as Fairness: A Restatement (Cambridge, MA: Harvard University Press, 2001), p. 131; T. M. Scanlon, The Diversity of Objections to Inequality, in The Difficulty of Tolerance. Essays in Political Philosophy (Cambridge: Cambridge University Press, 2003), pp. 202-18; Shlomi Segall, Health, Justice and Luck (Princeton: Princeton University Press, 2010); Christopher Freiman, Why Poverty Matters Most: Towards a Humanitarian
} 
Conversely, some philosophers defend thresholds that signal excess rather than deficiency. According to Ingrid Robeyns, for example, the fact that many people are deprived of basic needs supports limitarianism, which is the view that people should not have more than a certain amount of wealth. ${ }^{11}$ Other examples of distributive limits are limits on the usage of ecological resources. ${ }^{12}$ For example, Breena Holland argues in favour of 'capability ceilings ${ }^{13}$ which limit the amount of resources that can be used to secure and promote capabilities and functionings.

Hence, if all theories of distributive justice that deploy thresholds are threshold views, this label applies to many distributive theories. To facilitate the discussion about the conceptual structure of such views, some terminology is needed (see Figure 1A). Threshold views say that there is a continuum of levels of a distributable good. Each specific level on that continuum signals how much someone has of that distributable good. What characterizes threshold views is that they define a threshold on such a continuum, which can be defined in absolute or relative terms. ${ }^{14}$ This threshold demarcates two ranges of levels. The first range contains the level of the threshold itself and all levels above the threshold (see range+). The second range contains all levels below the threshold (see range-).

Threshold views can deploy a single threshold or multiple thresholds. ${ }^{15}$ Threshold views with multiple thresholds can be vertical or horizontal. ${ }^{16}$ Vertical threshold views define three or more ranges on one continuum by positing two or more thresholds. To illustrate, the threshold view in Figure 1B demarcates three ranges, namely range+, which is above both thresholds, range*, which is between the thresholds, and

Theory of Social Justice, Utilitas, 24.1 (2012), 26-40; Fabian Wendt, Three Types of Sufficientarian Libertarianism, Res Publica, 25 (2019), 301-18.

${ }^{11}$ Cf. Robeyns, Having Too Much; Ingrid Robeyns, What, If Anything, Is Wrong with Extreme Wealth?, Journal of Human Development and Capabilities, 20.3 (2019), 251-66.

${ }^{12}$ For ecological limits, see Fergus Green, Ecological Limits: Science, Justice, Policy, and the Good Life, Philosophy Compass (forthcoming).

${ }^{13}$ Cf. Breena Holland, Ecology and the Limits of Justice: Establishing Capability Ceilings in Nussbaum's Capabilities Approach, Journal of Human Development, 9.3 (2008), 401-25.

${ }^{14}$ See $\$ 3.1$.

${ }^{15}$ Multi-threshold views are increasingly prominent in distributive justice, especially in sufficientarianism. For vertical threshold views, see Francisco Sales-Heredia, Distributive Criteria in the Design of Poverty Alleviation Programs: Mexico, 1992-2000 (unpublished PhD thesis, University of Warwick, 2003); Yitzhak Benbaji, The Doctrine of Sufficiency: A Defence, Utilitas, 17.03 (2005), 310-32; Sufficiency or Priority?, European Journal of Philosophy, 14.3 (2006), 327-48; Robert Huseby, Sufficiency: Restated and Defended, Journal of Political Philosophy, 18.2 (2010), 178-97; Sufficiency, Priority, and Aggregation, in What Is Enough? Sufficiency, Justice, and Health, ed. by Carina Fourie and Annette Rid (Oxford: Oxford University Press, 2017), pp. 69-84; Sufficiency and the Threshold Question; Efrat Ram-Tiktin, Basic Human Functional Capabilities as the Currency of Sufficientarian Distribution in Health Care, in What Is Enough? Sufficiency, Justice, and Health, ed. by Carina Fourie and Annette Rid (Oxford: Oxford University Press, 2017), pp. 144-63; Rudolf Schuessler, Sufficientarianism and the Measurement of Inequality, Moral Philosophy and Politics, 6.1 (2019), 147-73. For horizontal threshold views, see Martha C. Nussbaum, Women's Capabilities and Social Justice, Journal of Human Development, 1.2 (2000), 219-47; David V. Axelsen and Lasse Nielsen, Sufficiency as Freedom from Duress, Journal of Political Philosophy, 23.4 (2015), 406-26.

${ }^{16}$ Cf. Axelsen and Nielsen, Sufficiency as Freedom from Duress, pp. 413-14. 


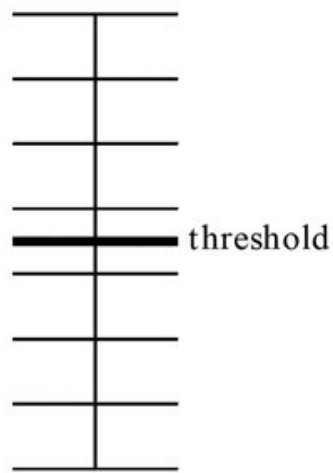

A. Threshold definition

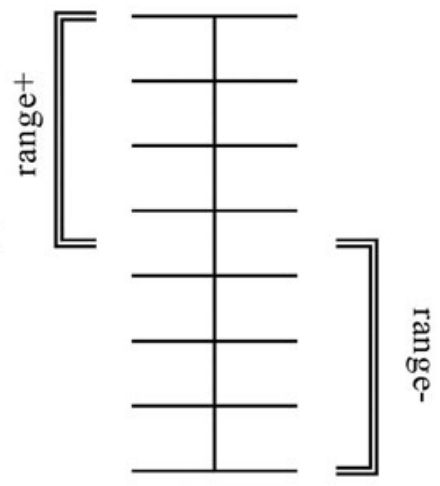

B. Range definition

Figure 2. Two definitions of threshold views.

range-, which is below both thresholds. ${ }^{17}$ Alternatively, horizontal threshold views specify a threshold for different distributable goods, essentially combining different continua and positing one or more thresholds in two or more of those continua. However, though multi-threshold views certainly merit discussion, I focus here on single-threshold views. The difference between them is that multi-threshold views posit more thresholds, and, consequently, more ranges. But everything there is to say about thresholds in multi-threshold views can be said by exploring thresholds in singlethreshold views. ${ }^{18}$

With the idea of a 'threshold', a 'continuum', and a 'range' in mind, we can define threshold views in two different ways (see Figure 2).

The threshold definition of threshold views: a threshold view defines a threshold on a continuum of some distributable good.

The range definition of threshold views: a threshold view defines different ranges on a continuum of some distributable good.

The threshold definition of threshold views and the range definition of threshold views are logically equivalent. If a view defines a threshold on a continuum, then it defines different ranges on that continuum. And conversely, if it defines different ranges on a continuum, then it defines a threshold on that continuum. What distinguishes the two definitions is which analytical commitment they foreground: a commitment to a threshold or a commitment to ranges.

In $\$ 6$, I will argue that recognizing the difference between these two definitions of threshold views strengthens the case against the arbitrariness objection. But the two

\footnotetext{
${ }^{17}$ For example, see Benbaji, The Doctrine of Sufficiency; Benbaji, Sufficiency or Priority?; Huseby, Sufficiency; Huseby, Sufficiency and the Threshold Question. For an example in applied ethics, see Erik Gustavsson and Niklas Juth, Principles of Need and the Aggregation Thesis, Health Care Analysis, 27.2 (2019), 77-92.

${ }^{18}$ One exception to this is that multi-threshold views allow for more types of clashes between allocative principles. See $\$ 3.3 .3$ and n. 26 .
} 
definitions are also insightful in that they tell us something about the scope of distributive theories that qualify as threshold views. Some theories of distributive justice propose an explicit threshold and are most intuitively categorized under the threshold definition of threshold views. For example, sufficientarianism holds that it is important that people secure a threshold level of some distributable good(s). ${ }^{19}$ Alternatively, limitarianism holds that people have too much if they exceed some wealth threshold. ${ }^{20}$ It is difficult to characterize these views without mentioning the threshold explicitly. In sufficientarianism, the threshold signals the level of goods people should have, and in limitarianism it signals the level of goods people should not exceed. Views which express their most central commitments in terms of 'having enough' and 'having too much', then, are therefore most naturally categorized under the threshold definition of threshold views.

Other distributive theories endorse thresholds without explicitly positing a threshold and may be more naturally categorized under the range definition of threshold views. Consider the widely shared endorsement of humanitarian reasons to benefit people. Martin O'Neill argues that egalitarians can base their motivation for being concerned about equality on the premise that inequality may prevent people from satisfying their basic needs. But even if this type of egalitarianism does not define an exact threshold at which basic needs are met, it does rely on the idea that there is a range on the continuum in which people do not have enough. ${ }^{21}$ O'Neill goes on to suggest that the value of such poverty alleviation 'counts in favor of distributive equality' not because the underlying beliefs are 'distinctively egalitarian' but because of 'underlying reasons which are themselves simply humanitarian'. ${ }^{22}$ But this simply means that egalitarians too care about people having enough of some distributable goods. And the same is true for all other theories of distributive justice which defend such a basic needs threshold or social minimum, even if they do not specify a particular threshold.

Hence, a theory of distributive justice is a threshold view if it posits a threshold demarcating different ranges on a continuum of some distributable good. I do not distinguish between threshold views that explicitly rely on a threshold and threshold views which do not. The conceptual structure I have outlined here applies to all views which deploy thresholds. The relative weight proponents of these specific distributive theories give to the threshold is a different matter.

\section{The concept of a threshold}

With the analysis of the structure of threshold views in mind, we can now take a closer look at the thresholds such views deploy. Threshold views posit a threshold to specify what a just allocation of distributable goods requires. The concept of such a threshold comprises three elements. These elements are (i) the level of the threshold, (ii) what constitutes the value of the threshold, and (iii) how benefits between and within ranges must be allocated. Few threshold views specify each of these elements in detail. But a fully fleshed out distributive theory that draws on thresholds should specify each of

\footnotetext{
${ }^{19}$ Cf. Casal, Why Sufficiency Is Not Enough.

${ }^{20}$ Cf. Robeyns, Having Too Much, p. 2; Zwarthoed, Autonomy-Based Reasons for Limitarianism.

${ }^{21}$ Cf. O'Neill, What Should Egalitarians Believe?, p. 121; see also Rawls, Justice as Fairness, p. 131; Scanlon, The Diversity of Objections to Inequality.

${ }^{22} \mathrm{O}$ 'Neill, What Should Egalitarians Believe?, pp. 26-27.
} 


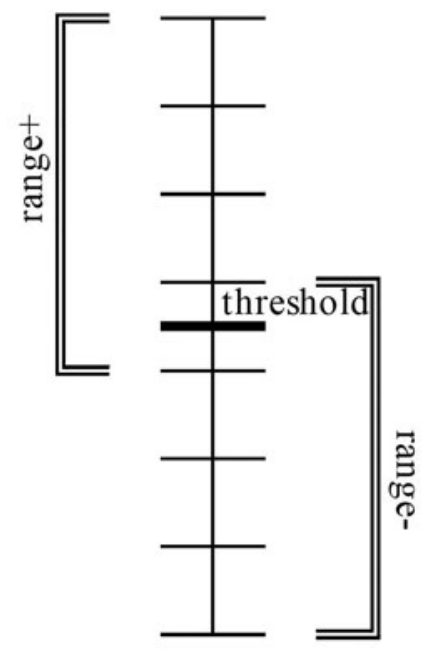

\section{A. A vague threshold}

Figure 3. The level of the threshold.

them, or at least offer guidance on how they should be specified. I will discuss the different elements of the concept of a threshold in turn.

\subsection{The level of the threshold}

The first element of the concept of a threshold is its level. We can set the level of the threshold by specifying its exact level or by positioning specific levels on the continuum in specific ranges.

The level of the threshold shows which range each level on the continuum belongs in. Sometimes, knowing that specific levels are in specific ranges tells us everything we need to know about the level of the threshold. For instance, without agreeing on an exact poverty line, we may reach a consensus on some levels being clear cases of deprivation. Here it is not a problem if the exact level of the threshold is unclear. But we may disagree about whether higher levels still count as cases of deprivation, which makes the issue of the exact level of the threshold more important.

This relates to a broader point about the 'exactness' of the threshold. Some threshold views allow room for uncertainty about its exact level. A threshold view could say that the border between range+ and range- is not clearly demarcated, such that for some levels it is unclear exactly which range they are in (see Figure 3). We need additional principles to decide how levels within the overlapping range should be treated. For instance, perhaps they should be treated as though they are in the range below the threshold. Or perhaps the burden of proof is with those who regard them as being above the threshold. Alternatively, decision-makers may have to exercise their discretionary power regarding levels in the overlapping range.

Aside from defining precise or vague thresholds, we can identify at least two ways of setting the level of threshold. An absolute threshold says that the level of the threshold does not change depending on how much others have. Alternatively, a relative 
threshold is determined in relation to the actual allocation of the distributable good. Consider the poverty threshold as an example, which is arguably the most widely accepted threshold in theories of distributive justice. According to absolute poverty thresholds, the poverty threshold can be set without reference to the allocation of distributable goods. An example of such a threshold is a threshold signalling necessary nutrition intake for subsistence, which is set with reference to the calories necessary for a person to stay alive but has no relation to how much others have (if my nutrition intake is too low to stay alive, this is true irrespective of your nutrition intake). ${ }^{23}$ Alternatively, relative poverty thresholds specify the poverty threshold by referring to how much other people have. For example, a relative poverty threshold could say that everyone in the lowest income percentile counts as being poor. Or the threshold can be set with reference to the average or median level of some distributable good, the minimum income, or some other standard.

The level of the threshold is intertwined with other elements of threshold views as theories of distributive justice. In particular, it can only be set with reference to the metric of justice, such as welfare, resources, or capabilities. The metric of justice specifies what the continuum is a continuum of (e.g. levels of welfare). In doing so, it determines what people have enough of when they reach the threshold (e.g. enough welfare), or what they have too much of when they exceed the threshold (e.g. too much welfare).

\subsection{The value of the threshold}

The second element of the concept of a threshold is what constitutes the value of the threshold, which can be intrinsic and/or instrumental. If the value of reaching some threshold cannot be solely derived from some other value(s), reaching that threshold has intrinsic value. However, if the value of reaching that threshold can be derived from some other value(s), reaching that threshold has instrumental value.

To illustrate, someone who defends a basic needs threshold as an efficient way of promoting social stability or security need not believe that it is particularly valuable for people to meet their basic needs. Instead, they believe that allowing people to do so is valuable because it promotes those other moral concerns. Others, however, may attach intrinsic value to such a threshold, for example because it indicates that people who can satisfy their basic needs can live a minimally decent life. Moreover, thresholds can have both instrumental value and intrinsic value. For instance, a basic needs threshold can be valuable both because it is good to be able to meet one's basic needs and because allowing people to meet their basic needs promotes some other moral concern(s).

\subsection{The allocative principles}

The allocative principles are the third element of the concept of a threshold; they specify how benefits and losses ('benefits' for short) within and between ranges must be allocated. Consider the following distributions, assuming the level of the threshold is 10 .

\footnotetext{
${ }^{23}$ Cf. Loganaden Naiken, FAO Methodology for Estimating the Prevalence of Undernourishment, Proceedings of International Symposium on Measurement and Assessment of Food Deprivation and Undernutrition (Rome: Food and Agriculture Organization of the United Nations, 2003), pp. 7-42.
} 


\begin{tabular}{rcccc}
\hline & Kourtney & Kim & Khloé & Rob \\
\hline$A$ & 9 & 9 & 50 & 500 \\
\hline$B$ & 1 & 10 & 15 & 15 \\
\hline
\end{tabular}

Suppose we must choose between $A$ or $B$. Which should we choose? Threshold views specify three types of allocative principles that should be used to answer this question. First, (non-)headcount principles specify how benefits must be allocated between ranges. Second, range principles specify how benefits must be allocated within ranges. Third, priority rules specify how benefits must be allocated if there is a clash between (non-)headcount principles and range principles. I will discuss these allocative principles in turn.

\subsubsection{Headcount principles versus non-headcount principles}

The first type of allocative principle specifies how to allocate benefits between different ranges. A headcount principle says that we must maximize the number of people above or below the threshold. ${ }^{24}$ Such a principle could prefer $B$, in which only Kourtney is below the threshold, over $A$, because in $A$ both Kourtney and Kim are below the threshold. Headcount principles are plausible principles in specific cases. If, for example, no one below the threshold will survive some grave injury, then it may be better to perform as many life-saving operations as possible - meaning that it would be better to apply a headcount principle. A headcount principle, then, prioritizes benefiting people just because that pulls them over the threshold, but it may withhold benefits altogether from people further below the threshold if the benefit they could receive would not be enough to get them up to the threshold.

However, many people reject headcount principles. It seems unjust to maximize the number of people above or below the threshold instead of ensuring, say, that people get as close to the threshold as possible. For example, Kourtney, who is the worst-off in both distributions, is much worse-off in $B$ than in $A$, yet headcount principles would prefer $B$ over $A$ nonetheless. ${ }^{25}$ Alternatively, then, threshold views can endorse a non-headcount principle, which says that we need not maximize the number of people above or below the threshold. If that is the case, the number of people on a specific side of the threshold is of limited importance compared with something like the degree to which people fall below the threshold.

Hence, most threshold views reject headcount principles and endorse nonheadcount principles instead. However, in $\$ 5 \mathrm{I}$ will argue that this rejection of headcount principles is too quick. Many critics of headcount principles, and all those who self-identify as sufficientarians in particular, should endorse such principles. But first we must turn to the other types of allocative principles.

\subsubsection{Range principles}

Range principles specify how distributable goods in a specific range must be allocated. Such range principles can be any of the common distributive patterns (except patterns that include a threshold). Range principles can be egalitarian, prioritarian, utilitarian, libertarian, or maximin, or specify some other patterned or non-patterned principle of distributive justice.

\footnotetext{
${ }^{24}$ For discussion, see Richard J. Arneson, Perfectionism and Politics, Ethics, 111.1 (2000), 37-63 (pp. 56-57); Casal, Why Sufficiency Is Not Enough, pp. 315-16; Segall, Health, Justice and Luck, p. 40.

${ }^{25} \mathrm{On}$ the assumption that the number of people above rather than below the threshold should be maximized.
} 
To illustrate, consider the following distributions, assuming the threshold is set at 10 .

\begin{tabular}{ccccc}
\hline & Kourtney & Kim & Khloé & Rob \\
\hline$A$ & 9 & 9 & 50 & 500 \\
\hline$C$ & 4 & 8 & 14 & 50 \\
\hline
\end{tabular}

An egalitarian range principle above the threshold would prefer $C$ over $A$ because $C$ has a more equal distribution above the threshold than $A$. And a deficiency-minimizing range principle below the threshold would prefer $A$ over $C$ because in $A$ the total deficiency from the threshold is lowest ( 2 in $A$ versus 8 in $C$ ). And there are more, almost endless, variations of possible range principles above and below the threshold.

\subsubsection{Priority rules}

Priority rules are allocative principles which offer guidance in cases where headcount principles and range principles rank distributions differently. This can be because (i) a headcount principle conflicts with one or more range principles or because (ii) different range principles conflict with each other. ${ }^{26}$

Recall the following distributions, assuming the level of the threshold is 10 .

\begin{tabular}{rrrrr}
\hline & Kourtney & Kim & Khloé & Rob \\
\hline$A$ & 9 & 9 & 50 & 500 \\
\hline$B$ & 1 & 10 & 15 & 15 \\
\hline$C$ & 4 & 8 & 14 & 50 \\
\hline
\end{tabular}

Let me give two examples of conflicting allocative principles. First, consider a threshold view which posits a headcount principle that has no preference between $A$ and $C$. Let us assume that this view specifies an egalitarian range principle above the threshold and a similar egalitarian principle below the threshold. Consequently, for the range below the threshold, this view prefers $A$ over $C$ because $A$ is more equal below the threshold. But for the range above the threshold, it prefers $C$ over $A$ because $C$ is more equal above the threshold. Here, a priority rule must settle which range principle should have priority. Second, consider a threshold view which prefers $B$ over the other distributions because in $B$ most people are above the threshold. But suppose that view defends a range

\footnotetext{
${ }^{26}$ If the threshold view is a multi-threshold view, this can also be the case because a headcount principle conflicts with another headcount principle, or because different range principles and different headcount principles are in conflict with each other. For example, the first headcount principle could say that we must maximize the number of people above the first threshold, and the second headcount principle could say that we must maximize the number of people above the second threshold. But this leads to conflicts if one distribution maximizes the number of people above the first threshold but not the above second threshold and if the second distribution maximizes the number of people above the second threshold but not above the first threshold.
} 
principle below the threshold which prefers $C$ and $A$ over $B$, because in $B$ Kourtney is worst-off. Hence, such a view ranks $B$ highest on the basis of its headcount principle, but it ranks $B$ lowest on the basis of its range principle below the threshold. In this case, then, a priority rule must establish whether the headcount principle or range principle has priority.

There are two types of priority rules that can be used to settle such conflicts: lexical priority rules and weighted priority rules. A lexical priority rule gives absolute priority to one allocative principle over other principles. To illustrate, if a headcount principle has lexical priority over the range principle below the threshold, which, in turn, has lexical priority over the range principle above the threshold, then the theory ranks distributions by looking first at what the headcount principle prefers, and between distributions that are equal in that regard it gives priority to distributions preferred by the first range principle and then to distributions preferred by the second range principle.

Alternatively, a weighted priority rule states that allocative principles must be weighed against each other. There are many possible variations that can be made when assigning relative weight to each of the principles. To give one example, a threshold view could give weighted priority to a prioritarian distribution below the threshold, which gives it reason to prefer $A$ over $C$. Yet it could also hold that the inequality above the threshold in $A$ is so great that this justifies preferring $C$ over $A$, all things considered. Hence, a weighted priority rule says that we have justice-relevant reasons to prefer certain distributions over others and that we must weigh those different reasons and their respective rankings to come to an all-things-considered ranking as far as the allocative principles are concerned.

\section{What happens at the threshold?}

Threshold views define a threshold as demarcating ranges on a continuum of some distributable good. I have argued that the concept of a threshold that such views draw on has three elements, namely a level, a value, and allocative principles, i.e. (non-)headcount principles, range principles, and priority rules. In the following sections, I highlight three insights that this analysis of thresholds and threshold views provides, that is, insights into what happens at the threshold, into headcount principles, and into the arbitrariness objection.

The first insight concerns what it is exactly that a threshold denotes. One common and insightful way of specifying the role that thresholds play in distributive justice is to say that they denote a 'shift' or 'discontinuity in the weight of our reasons'. This idea is developed by Liam Shields in his analysis of sufficientarianism. ${ }^{27}$ The analysis of thresholds in this article can deepen our understanding of what such shifts or discontinuities amount to. Aside from the fact that Shields' analysis focuses on sufficientarianism whereas my account is broader and applies to all threshold views in distributive justice, I will argue that my analysis provides two further benefits. First, it gives a more accurate and comprehensive description of the kinds of shifts that can occur at the threshold. Second, it can more easily further debates on thresholds in non-sufficiency views.

\footnotetext{
${ }^{27}$ Cf. Shields, The Prospects for Sufficientarianism; Liam Shields, Just Enough: Sufficiency as a Demand of Justice (Edinburgh: Edinburgh University Press, 2016); Liam Shields, Reply to Critics, Law, Ethics and Philosophy, 5 (2018), 210-30.
} 
Shields argues that a threshold demarcates a 'shift in our reasons to benefit people once they have secured enough' ${ }^{28}$ More precisely, Shields defines the shift thesis as follows:

The shift thesis: once people have secured enough there is a discontinuity in the rate of change of the marginal weight of our reasons to benefit them further. ${ }^{29}$

According to Shields, this shift or discontinuity can be explained by one of two things. ${ }^{30}$ First, it could result from a justice-relevant satiable reason. If a particular reason(s) for benefiting someone is sated once they secure a certain amount of goods, then once they reach that level our reasons for benefiting them change. For example, if we benefit Kourtney to lift her from poverty, then once she is no longer living in poverty, that reason for benefiting her is sated. We may still have reasons to benefit Kourtney, but those reasons cannot include the reason that she must be free from poverty. Second, the shift could result from a change in the relative weight of our reasons to benefit someone. Suppose we have two reasons to benefit someone, but the first reason has increasingly less weight the more goods they have and the second reason has the same weight no matter how many goods they have. If this is the case, the more goods someone has, the weightier the second reason becomes compared with the first reason, up to the point where the second reason has more weight than the first reason. The point at which the weight of these two reasons is the same is the point at which a shift in our reasons to benefit people occurs, and therefore that is where the threshold is.

The idea of a shift or discontinuity is helpful for understanding and specifying the role that thresholds play in distributive justice, but to fully achieve this, we must qualify Shields' analysis in light of my conceptual analysis. The first reason for having to do this is straightforward: Shields is interested in sufficientarianism and the issue of what sufficientarians should believe, whereas I am interested in the structure of threshold views in distributive justice more generally. ${ }^{31}$ Shields therefore excludes instrumental thresholds from his analysis, because he argues that sufficientarians should defend intrinsic thresholds. ${ }^{32}$ Furthermore, the shift thesis is phrased to capture thresholds which signal sufficiency and not, for example, excess. $^{33}$ This is because it says that the discontinuity applies 'once people have secured enough'. ${ }^{34}$ These differences set the analysis in this article apart from Shields' analysis in the sense that my analysis is broader and aims to capture a wider range of views.

Yet the main contribution of the account provided in this article is not that it applies more broadly than Shields' account but that it can deepen our understanding of the possible shifts and discontinuities that may occur at the threshold. Consider again Shields' claim that the threshold signals a discontinuity in the weight of our reasons to benefit someone, which occurs either because a reason is sated or because of some

\footnotetext{
${ }^{28}$ Shields, The Prospects for Sufficientarianism, p. 102.

${ }^{29}$ Ibid., p. 108.

${ }^{30}$ Cf. Shields, Reply to Critics, p. 212.

${ }^{31}$ For example, Shields argues that the shift thesis should replace the more common 'negative thesis' as a prerequisite for a sufficientarian view. See Shields, The Prospects for Sufficientarianism.

${ }^{32}$ Cf. ibid., pp. 112-13. Some might think that instrumental thresholds are only trivial thresholds in the sense that they are only a means to promote some end rather than being intrinsically valuable. However, the structure of threshold views does not depend on whether or not the threshold is intrinsically valuable, and so there is no need to limit the scope of this analysis to either intrinsic or non-instrumental thresholds. I thank an anonymous reviewer for this point.

${ }^{33}$ Cf. ibid., pp. 112-13.

${ }^{34}$ Ibid., p. 108.
} 
significant change in the relative weight of a reason to benefit someone once they reach the threshold. However, such discontinuity could equally well be explained by one single reason, and it need not change the relative weight of our reason to benefit someone. For example, suppose our reason for benefiting people is that we endorse a principle of equal opportunity. This, it seems to me, implies that we must be concerned with both sufficiency and equality, and it is not evident that either of them matters more from the standpoint of justice. If people have less than a threshold level of goods (e.g. if they live in extreme poverty), equal opportunity cannot be secured because people lack the resources to pursue opportunities in the first place. ${ }^{35}$ But likewise, equality of opportunity can only be secured if the allocation of distributable goods among those above the threshold is sufficiently equal. This is because a vastly unequal distribution means that those who have the most goods have objectionably more opportunities than others. Consequently, equality of opportunity requires that people have enough goods to pursue opportunities but also that they have sufficiently equal amounts of goods when they are above the threshold. Hence, there need not be a change in reasons to benefit someone for there to be a discontinuity in how benefits should be allocated. In this case, for example, both above and below the threshold our reason for benefiting people is the principle of equal opportunity.

What this suggests is that aside from focusing on the types of reasons that justify a shift once people reach some threshold, we should also explore the types of shifts that thresholds can denote. One possible shift is a shift in the range principle according to which benefits must be allocated. A different range principle applies below the threshold than above the threshold. Even if both range principles are egalitarian, for example, the people among whom an egalitarian distribution must be achieved is different below and above the threshold. Another possible shift is a shift in the relative weight of a benefit above or below the threshold. A threshold view that is concerned with people having enough of some distributable good attaches more relative weight to the optimal distribution below the threshold than to the optimal distribution above the threshold. And conversely, a threshold view that is concerned with people not having an excess of some good attaches more relative weight to an optimal distribution above the threshold, such as by limiting the number of people above the threshold or by limiting the total amount of goods above the threshold.

More generally, then, if the concept of a threshold comprises a level, value, and allocative principles, all possible shifts can be characterized as a combination of specifications of each of those elements. This does not tell us why a shift should occur, but it does give us the conceptual machinery to characterize each possible shift.

Let me illustrate the value of this approach with an example that starts from a debate that is internal to one specific threshold view, namely sufficientarianism, but is insightful in many other contexts. Sufficientarianism is traditionally defined as combining the positive thesis that it is intrinsically valuable to have enough and the negative thesis that once people have enough, no further distributive criteria apply. ${ }^{36}$ The negative thesis, then, posits a specific type of shift which combines a range principle above the threshold that is indifferent about possible distributions with a priority rule that specifies

\footnotetext{
${ }^{35}$ Of course, according to a very minimal account of equality of opportunity, a world in which no one has opportunities satisfies this moral ideal. Here, however, I assume a more demanding conception of equality of opportunity.

${ }^{36}$ Cf. Casal, Why Sufficiency Is Not Enough.
} 
giving lexical priority to subthreshold benefits. ${ }^{37}$ But these priority rules and range principles can be different, resulting in different shifts that the threshold gives rise to.

To give another example, Campbell Brown argues in favour of 'threshold prioritarianism', which holds that we must give priority to benefiting those below some threshold and that once we cannot benefit them any further, we must turn to others and benefit them, giving priority to those who are worse-off. ${ }^{38}$ Hence, this type of prioritarianism combines a prioritarian range principle above some threshold and a similar range principle below that threshold, and gives lexical priority to benefits below that threshold. The benefit of this distributive view over standard prioritarianism is that it does not entail that any loss to a worse-off person, no matter how large, could be outweighed by benefits to a group of better-off people, no matter how small, if the number of the better-off persons is large enough. However, Matthew D. Adler and Nils Holtug reject threshold prioritarianism and adopt standard prioritarianism instead because they consider it 'counterintuitive that morality includes a threshold across which absolute priority obtains'. ${ }^{39}$ Although this indeed targets the structure of Brown's proposal, we can now see that it could easily be amended to strike a balance between both Brown's reason for proposing a threshold and Adler and Holtug's reason for rejecting it. For example, instead of threshold prioritarianism giving lexical priority to subthreshold benefits, it could give weighted priority to subthreshold benefits. Or instead of giving lexical priority to subthreshold benefits, it could deploy some sort of headcount principle.

Hence, the nature of the shift that occurs at the threshold can be characterized by saying that it specifies the different elements of the concept of a threshold. This account supplements Shields' analysis of thresholds by being more comprehensive and precise in its specification of possible shifts that might occur at the threshold and by being capable of applying to all kinds of threshold views, including non-sufficientarian ones.

\section{What's wrong with headcounting?}

The second insight that the analysis of thresholds provides is that we must reconsider a received wisdom about - or, according to most philosophers of distributive justice, against - headcount principles. This received wisdom, which is that headcount principles must be rejected, is especially clear in the literature on sufficientarianism, but others may reject such principles on similar grounds. ${ }^{40}$ I will argue that this rejection relies on a misunderstanding of the role that headcount principles play in threshold views. In fact, showing why this is a misunderstanding suggests that sufficientarians and other proponents of intrinsic thresholds should endorse headcount principles and that, at least in my view, proponents of headcount principles have not defended such principles in the strongest possible way.

\footnotetext{
${ }^{37}$ See also Huseby, Sufficiency and the Threshold Question.

${ }^{38}$ Cf. Brown, Priority or Sufficiency... or Both?; Campbell Brown, Prioritarianism for Variable Populations, Philosophical Studies, 134.3 (2007), 325-61.

${ }^{39}$ Matthew D. Adler and Nils Holtug, Prioritarianism: A Response to Critics, Politics, Philosophy \& Economics, 18.2 (2019), 101-44 (p. 132).

${ }^{40}$ For example, see John E. Roemer, Eclectic Distributional Ethics, Politics, Philosophy \& Economics, 3.3 (2004), 267-81 (pp. 278-79); Jonathan Wolff and Avner De-Shalit, Disadvantage (Oxford: Oxford University Press, 2007), pp. 91-93; Shlomi Segall, Equality and Opportunity, 1st edn (Oxford: Oxford Univ. Press, 2013), p. 137, n. 10.
} 
Shields' discussion of headcount principles illustrates the received wisdom about such principles and the reasoning behind their assumed implausibility. He argues that sufficiency principles which deploy headcount principles, i.e. headcount sufficiency, 'assess distributions solely in terms of the number of people who have secured enough in each distribution'. ${ }^{41}$ Shields gives the following counterexample against headcount sufficiency:

[C]onsider a threshold of 100 units, where 100 units represents being very well-off and 1 unit represents being extremely badly off. A version of headcount sufficientarianism will hold that we should benefit the person with 99 units by 1 unit at the expense of benefiting the person with 1 unit by 98 units, but this seems to be the wrong answer. In this case it seems that we should benefit the very badly off person by 98 units. $^{42}$

Put differently, headcount sufficiency prefers distribution $D$ over $E$ where the threshold is set at 100:

\begin{tabular}{ccc}
\hline & Kendall & Kylie \\
\hline$D$ & 100 & 1 \\
\hline$E$ & 99 & 99 \\
\hline
\end{tabular}

Preferring $D$ over $E$ seems unjust unless the threshold is very low (see \$3.3.1). If the threshold signals the point above which people are 'very well-off', this is not the case. Therefore, we must reject headcount sufficiency.

Shields and other critics of headcounting can hardly be blamed for this interpretation of headcount principles. ${ }^{43}$ Proponents of headcounting have stated their views in exactly those words, which, in my view, has led them to significantly undersell the value of headcounting in distributive justice. For example, Harry Frankfurt proposes 'to distribute the available resources in such a way that as many people as possible have enough or, in other words, to maximize the incidence of sufficiency. ${ }^{44}$ And Dale Dorsey says that 'the state of affairs with more rather than fewer individuals obtaining the basic minimum is, no matter the arrangements below and above the minimum, [better]'. ${ }^{45}$ This is precisely what Shields opposes, and though I will argue that Shields' objection does not apply to headcount principles as such, it is certainly a valid objection to these defences of headcounting.

The problem with the common refutation of headcount principles is that it relies on a misunderstanding about the role headcount principles play in threshold views. Likewise, proponents of these principles have also failed to take into account possible and, arguably, more plausible variations of headcounting in threshold views. The received wisdom is right about one thing: headcount principles say that we must maximize the number of

\footnotetext{
${ }^{41}$ Shields, The Prospects for Sufficientarianism, p. 103.

${ }^{42}$ Ibid., p. 103.

${ }^{43}$ I thank an anonymous reviewer for this point.

${ }^{44}$ Harry Frankfurt, Equality as a Moral Ideal, Ethics, 98.1 (1987), 21-43 (p. 31).

${ }^{45}$ Dale Dorsey, Toward a Theory of the Basic Minimum, Politics, Philosophy \& Economics, 7.4 (2008), 423-45 (p. 437).
} 
people above or below the threshold. However, that does not mean, as Shields puts it, and as Frankfurt and Dale suggest, that headcount sufficiency needs to assess 'distributions solely in terms of the number of people who have secured enough in each distribution'. ${ }^{4}$ This disregards the distinction between headcount principles as a type of allocative principle and headcount principles that are combined with a lexical priority rule. Put differently, it confuses headcount principles as a type of allocative principle with headcount principles that have lexical priority over other allocative principles.

Headcount principles rank distributions based on the number of people above or below the threshold. But they do not say what the relative importance of this ranking is compared with rankings proposed by other allocative principles. Hence, headcount principles give a reason in favour of specific distributions. But other allocative principles can give reasons in favour of other specific distributions. For example, headcount sufficiency can prefer $D$ over $E$ because in $D$ more people are above the threshold. However, its range principle below the threshold could prefer $E$ over $D$ because $E$ benefits the least advantaged. A headcount sufficiency view which combines such a headcount principle and such a range principle, then, includes reasons both in favour of $D$ and in favour of $E$. But it need not give priority to headcounting over other distributive concerns. The relative weight that headcount sufficiency attaches to headcounting depends on its priority rules.

Hence, a headcount principle says that we must maximize the number of people above or below the threshold. It does not say that maximizing the number of people above or below the threshold has lexical priority over other moral concerns - that would involve a combination of a headcount principle and a lexical priority rule. Rather, it says that a distribution that maximizes the number of people above or below the threshold is preferable in at least one regard to a distribution which does not do so, just as an egalitarian range principle says that an egalitarian distribution is preferable in at least one regard to an inegalitarian distribution.

Consequently, the difference between headcount sufficiency and non-headcount sufficiency is that headcount sufficiency attaches distinctive value to people reaching the threshold whereas non-headcount sufficiency does not. ${ }^{47}$ Headcount sufficiency says that because it is only in $D$ that Kendall has 'enough', $D$ is preferable to $E$ in at least one way. Conversely, non-headcount sufficiency rejects that $D$ is in any distinctive way preferable to $E$ because it is only in $D$ that Kendall reaches the threshold. Put differently, a non-headcount principle is indifferent to the fact that someone reaches the threshold, but headcount principles attach distinct value to people reaching the threshold. Contrary to the received wisdom, then, the role that headcount principles play in threshold views is providing a reason in favour of distributions which allow more people to reach the threshold rather than giving lexical priority to maximizing the number of people on a specific side of the threshold.

\footnotetext{
${ }^{46}$ Shields, The Prospects for Sufficientarianism, p. 103. Emphasis mine.

${ }^{47}$ Note that the distinction between headcount principles and non-headcount principles is different from that between instrumental thresholds and intrinsic thresholds. Instrumental thresholds can be combined with headcount principles and non-headcount principles. For instance, if the aim is to save as many lives as possible in order to win a war, we have an instrumental reason to apply a headcount principle. However, if the aim is to minimize crime, then we could posit some basic needs threshold which signals the point up to which additional benefits no longer correlate with lower levels of crime. But instead of lifting as many people as possible above that threshold, reducing crime might be better achieved by getting people as close to the threshold as possible. Here the instrumental threshold is combined with a non-headcount principle. Hence, the distinction between headcount principles and non-headcount principles is not the same as the distinction between instrumental thresholds and intrinsic thresholds.
} 
This brings us to why sufficientarians should defend headcount principles. Sufficientarians hold that reaching the threshold is intrinsically valuable, meaning, for example, that it is intrinsically valuable not to live in deprivation, live a minimally decent life, or achieve some other threshold level of a distributable good. These things are intrinsically valuable because the value of having enough in this sense cannot be, or cannot entirely be, derived from some other value(s). But if it is intrinsically valuable to have enough, then there should be a distinctive value in someone having enough. For that reason, sufficientarians and others who defend intrinsic thresholds should defend a headcount principle. For sufficientarians, $D$ is preferable to $E$ in at least one way because in $D$ Kendall has enough, and it is intrinsically valuable to have enough. Whatever reason sufficientarians have for favouring $E$ over $D$ - and, certainly, they may have very good reasons to rank $E$ higher than $D$, all things considered - that reason cannot be that it does not matter if Kendall reaches the threshold.

A different way of putting this point is by describing what sufficientarians lose by rejecting headcount principles. If they reject those principles, they can still say that it is intrinsically valuable that people reach the threshold. However, they must deny that distributions in which some people reach the threshold are preferable to distributions in which no one reaches the threshold in at least one specific sense. That, to me, seems implausible; if it is intrinsically valuable to have enough, then it is valuable if people reach the threshold. ${ }^{48}$

Let me illustrate the type of sufficientarianism I have in mind here with two examples. The first is a version of headcount sufficientarianism that gives weighted but not lexical priority to headcounting. Consider the following three distributions, assuming that the threshold is set at 10 :

\begin{tabular}{ccc}
\hline & Kendall & Kylie \\
\hline$F$ & 9 & 8 \\
\hline$G$ & 10 & 7 \\
\hline$H$ & 10 & 1 \\
\hline
\end{tabular}

Many distributive views prefer $F$ to $G$ and $H$, for example because $F$ is more equal and because it maximizes the benefits to the worst-off. However, sufficientarians can prefer $G$ to $F$ because in $G$ Kendall reaches the threshold, and the value of someone reaching the threshold outweighs the loss to Kylie in this specific case. But those sufficientarians could still prefer $F$ to $H$, because even though Kendall reaches the threshold in $H$ too, the value of her reaching the threshold is not enough to outweigh Kylie's loss in that specific case.

The second example is a headcount sufficiency view that gives lexical priority to the range principle below the threshold. Such a view says that we must first rank distributions on the basis of the range principle below the threshold, and among distributions that are equal in that respect, the distribution in which most people are above the threshold is

\footnotetext{
${ }^{48}$ Some proponents of headcounting might say that giving headcount principles lexical priority is attractive because it gives the greatest priority to those who are desperate. That is compatible with my analysis, as its main contribution is to show that headcount principles may but need not have lexical priority, whereas the common interpretation in the literature assumes that headcounting has lexical priority.
} 
preferable. Both types of headcount sufficientarianism illustrate the kind of sufficientarianism I am advocating here. And if my argument is correct, sufficientarians and other proponents of intrinsic thresholds should defend a version of this view as well.

A critic could say that this defence of headcount principles does not solve the problem raised by Shields. ${ }^{49}$ The defence still says that justice requires benefiting the betteroff below the threshold by tiny amounts instead of the worse-off by much larger amounts, if that allows the better-off to exceed the threshold. Giving weighted priority rather than lexical priority to this principle only means that it applies in one respect rather than all things considered. So one might say that instead of solving the problem, this response only limits its objectionable implications.

However, the fact that a principle is implausible as an all-things-considered principle need not render it implausible as a pro tanto principle. Proponents of headcount principles can respond to Shields' objection by saying that it does not apply less to headcount principles that have weighted priority but that it does not apply to them at all. They can grant that giving headcount principles lexical priority is objectionable without agreeing that this shows something about the nature of headcount principles. So if Shields says that headcount sufficientarianism seems to give the 'wrong answer' if it says that we should 'benefit the person with 99 units by 1 unit at the expense of benefiting the person with 1 unit by 98 units', ${ }^{50}$ then this wrong answer does not result from headcounting as such but from failing to see the proper place for headcounting in threshold views. Furthermore, I have argued that sufficientarians should endorse headcount principles because they defend an intrinsic threshold. Consequently, if headcount principles should be rejected even if they apply only in one respect, then this challenges sufficientarianism in general, because all these views endorse intrinsic thresholds, not just sufficientarian views which give lexical priority to headcounting.

Hence, the received wisdom that headcount principles must be rejected rests on a misunderstanding. It mistakenly assumes that headcount principles must have lexical priority. But instead of saying that headcount principles claim that we should always maximize the number of people who secure enough, we should say that they attach distinct value to people securing enough. This is precisely the kind of thing that sufficientarians must say if they defend intrinsic thresholds. Therefore, sufficientarians should endorse headcount principles.

\section{The arbitrariness objection}

The third insight that the analysis of thresholds provides concerns the most common objection to threshold views: the arbitrariness objection. This objection says that no particular level on the continuum can be pointed out as the level of the threshold, and this is worth reflecting on here. Proponents of threshold views sometimes say that establishing a threshold non-arbitrarily is not much of a challenge, or that it is not necessary to have a clear answer to the arbitrariness objection. ${ }^{51}$ Yet the arbitrariness objection is so pervasive in discussions on threshold views in distributive justice that we cannot

\footnotetext{
${ }^{49}$ I thank an anonymous reviewer for raising this objection.

${ }^{50}$ Shields, The Prospects for Sufficientarianism, p. 103.

${ }^{51}$ For example, see Shields, Reply to Critics, p. 219. Note, however, that Shields says that the arbitrariness need not be answered in the context in which it is raised against his view. Yet threshold views more generally cannot say this, as they may be developed in contexts where the level of the threshold cannot be established by sufficientarian reasons (see also $\$ 4$ ).
} 
consider the role thresholds play in such theories without considering their alleged arbitrariness. ${ }^{52}$ At the very least, proponents of threshold views must acknowledge that others reject thresholds on the basis of their supposed arbitrariness. Furthermore, the analysis of threshold views suggests novel directions in which threshold views can be developed that become apparent in light of the arbitrariness objection.

The most straightforward response to the arbitrariness objection is that sometimes we simply know how high the threshold should be. For instance, suppose that justice is concerned with being well nourished. If so, as long as Kris has enough food, it does not matter if she has just enough or much more than that. Kris may have reasons other than 'being well nourished' to want to have more food, but if that is the only justice-relevant reason, those other reasons do not constitute demands of justice. This answers the arbitrariness objection. Lacking sufficient food means that one does not meet the threshold, having enough food is enough to meet the threshold, and having more than that is more than enough to meet the threshold. Hence, the threshold should be set at the point where people have enough to be well nourished, and once they have enough there is no longer a justice-relevant reason to benefit them further in this regard. Sometimes, then, we can specify a threshold non-arbitrarily.

However, drawing on the analysis of thresholds set out earlier, we can give another response to the arbitrariness objection. That some thresholds are arbitrary may be beside the point. For instance, even if the exact level of the threshold is disputed, there can be an agreement on the fact that certain levels are in a specific range. Sometimes all a threshold view needs to do is to say for a specific level in which range it is. But surgical precision need not be necessary for this. When the Boxing Day tsunami hit Indonesia, Sri Lanka, India, and Thailand on 26 December 2004, for example, there was little doubt that many people were deprived of access to basic justice-relevant goods such as food, housing, and healthcare. Regarding any reasonable basic needs threshold, then, it was evident that many people were deprived of their basic needs. And there was no need for a very precise threshold to show this. In some cases, the fact that some people are below the threshold is beyond reasonable doubt even if there is reasonable disagreement about the exact level of the threshold.

The more general point here is that the arbitrariness objection reduces the plausibility of threshold views in distributive justice to whether they can set the level of the threshold. But it is crucial to appreciate the fact that talking about thresholds implies talking about ranges; and that, conversely, talking about ranges implies talking about thresholds. So as well as showing that thresholds need not be arbitrary, or that arbitrariness is not always a problem, we can also argue that we have good reasons to distinguish different ranges. If we have good reasons to distinguish ranges, then, by definition, we have good reasons to endorse thresholds.

Moreover, we do have good reasons to distinguish between different ranges. Such ranges can correspond with notions of deficiency and excess, and are broadly supported and appeal to widely shared intuitions about social policy in distributive issues. The notion of deficiency is particularly widespread, and it rests on the idea that some people have too little when they are below some adequate standard. Recall that, as White observes, the statements that people should not be allowed to starve in the streets or

\footnotetext{
${ }^{52}$ See, for example, Robert E. Goodin, Egalitarianism, Fetishistic and Otherwise, Ethics, 98.1 (1987), 4449 (p. 49); Arneson, Perfectionism and Politics, p. 56; Casal, Why Sufficiency Is Not Enough, pp. 312-14; Dale Dorsey, Equality-Tempered Prioritarianism, Politics, Philosophy \& Economics, 13.1 (2014), 45-61 (p. 50); Wolff and De-Shalit, Disadvantage, p. 92.
} 
that they should not be denied access to a decent minimum level of healthcare are widespread political views. ${ }^{53}$ Many institutions of the welfare state aim to help people secure a level of basic goods such as food, access to healthcare and education, and housing. To the extent that such positions are defended by theories of distributive justice, those theories assume a commitment to different ranges, and, consequently, to thresholds.

\section{Concluding remarks}

Threshold views are theories of distributive justice which draw on thresholds to specify how distributable goods should be allocated. Such views are prominent in various areas of distributive justice, ranging from abstract distributive patterns such as sufficientarianism and limitarianism to applied issues in the contexts of healthcare, education, and climate ethics. I have distinguished between three elements of the concept of a threshold that such views deploy, which are as follows:

(i) the level of the threshold, which

a. determines the exact level of the threshold; and/or

b. positions specific levels in specific ranges; and

(ii) what constitutes the value of the threshold, which can be

a. intrinsic value; and/or

b. instrumental value; and

(iii) the allocative principles, which are

a. a headcount principle and/or a non-headcount principle; and

b. range principles; and

c. a priority rule.

Any complete specification of a threshold view in distributive justice must be defined in terms of these different elements. In this article I have not argued in favour of specific threshold views but have merely aimed to show what unites the more specific conceptualizations of such views. Furthermore, I have highlighted three ways in which this conceptual analysis benefits the current debate on threshold views in distributive justice. It shows the distributive implications of the shift that occurs once people reach the threshold; it shows that common objections to headcount principles must be reconsidered and that sufficientarians must endorse headcounting; and it shows how proponents of threshold views can deal with the arbitrariness objection. ${ }^{54}$

Competing interests. The author declares none

\footnotetext{
${ }^{53}$ Cf. White, Social Minimum.

${ }^{54}$ For especially helpful discussion and comments on earlier drafts of this article, I thank Fergus Green, Daniel Halliday, Colin Hickey, Sem de Maagt, Tim Meijers, and Ingrid Robeyns. I am also grateful to the reviewers of this journal for their detailed and thoughtful feedback. This project has received funding from the European Research Council (ERC) under the European Union's Horizon 2020 research and innovation programme (grant agreement no. 726153).
}

Cite this article: Timmer D (2021). Thresholds in Distributive Justice. Utilitas 33, 422-441. https://doi.org/ $10.1017 /$ S0953820821000194 